\title{
Role of Colored Pan Traps for Insect Pollinator Diversity in Bitter Gourd Ecosystem in Surguja of Chhattisgarh
}

\author{
G.P. Painkra* \\ IGKV, All India Coordinated Research Project on Honey Bees and Pollinators, Department of \\ Entomology, RMD College of Agriculture and Research Station, Ambikapur 497001 \\ Chhattisgarh, India \\ *Corresponding author
}

\begin{tabular}{|l|}
\hline K e y w o r d s \\
Bitter gourd \\
$\begin{array}{l}\text { Ecosystem, Colored } \\
\text { pan trap, Habitat } \\
\text { and Pollinator/ } \\
\text { Visitor diversity }\end{array}$ \\
\hline Article Info \\
\hline $\begin{array}{l}\text { Accepted: } \\
\text { 24 November } 2018 \\
\text { Available Online: } \\
\text { 10 December } 2018\end{array}$ \\
\hline
\end{tabular}

A B S T R A C T
The study was undertaken at Raj Mohini Devi College of Agriculture and Research Station, Ambikapur during 2017-18 for diversity of insect pollinators/ visitors in bitter gourd ecosystem. Different insect pollinators/ visitors i.e. Apis dorsata, A. indica, A. florea, xylocopa, black ant and small ants were recorded in different fluorescent colored pan trap i.e. White, yellow and blue at different flowering period onset of bloom, full bloom and end of bloom of bitter gourd. In habitat $-\mathrm{I}$ at the onset of bloom maximum insect pollinators/visitors were recorded in blue pan trap (7.65 insect/trap) followed by yellow pan trap (5.98 insect/trap) and minimum in white pan trap (4.31 insect/trap) however, during full bloom period highest insect pollinators/visitors were observed in yellow pan trap (27.33 insect/trap) followed by in white pan trap (20.33 insect/trap) and lowest were recorded in blue pan trap (19.33 insect/trap) and at the end of bloom higher population was recorded in yellow pan trap (14.64 insect/trap) followed by in blue pan trap (12.98 insect/trap) and lower population were recorded in white 7.65 insect/trap. In habitat-II at the onset of bloom maximum population were found in yellow pan trap (21.98 insect/trap) followed by in blue pan trap (21.65 insect/trap) and minimum population were recorded in white pan trap (15.64 insect/trap) however, at the full bloom period highest insect population were recorded in blue pan trap (21.98 insect/trap) followed by in yellow pan trap (21.31 insect/trap) and lower population were found in in white pan trap (19.31 insect/trap) and at the end of bloom highest population were recorded in blue pan trap (17.98 insect/trap) followed by in yellow pan trap (17.31 insect/trap) and lowest in white pan trap(13.32 insect/trap).

\section{Introduction}

Pollinators are an important source of pollination which transfer the pollen from one flower to another due to which the yield is enhanced and harvest the good yield by the farmers. Pollination is depends on the availability of pollinators otherwise it is not possible to harvest the good yield. Bitter gourd is a good source of pollen due to which attract the polinizers and ultimately pollination process is complete for harvest of good yield. Various insect groups which are responsible for crop pollination which increase the crop 
yield i.e. Hymenoptera, Coloeptera, Diptera, Lepidoptera, Thysanoptera and Neuropteran.

Pollinators are actually diverse, with more than 16,000 pollinators bee species described worldwide (Kevan, 2003). Bees are responsible for almost 80 per cent of pollination and their role in increasing crop yield is well recognized (Teale, 1957). Pollination is an important process for the maintenance and promotion of biodiversity and, in general, life on earth. Many ecosystems, i.e. agro ecosystem depends on pollinators diversity for maintain the overall biological diversity. Pollination is also benefits to society by increasing food security and improving livelihoods (Khan and Khan,2004). The main objective of this study was to know the diversity and abundance of insect pollinators in the bitter gourd ecosystem.

\section{Materials and Methods}

The study was undertaken at Raj Mohini Devi College of Agriculture and Research Station, Ambikapur substation of Indira Gandhi Krishi Vishwavidyalaya, Raipur Chhattisgarh during 2017-18. Pollinator/ visitors diversity in two different habitats differentiated on the basis of aspect, vegetation and distance from water body was conducted in bitter gourd ecosystem at research station (Habitat-1) and at Ajirma (Habitat-2) of Surguja district. Diversity of insect visitors on bitter gourd were recorded during the flowering period of bitter gourd (April to June). During the study various fluorescent colored pan traps viz., white, yellow and blue were used and were placed before $0900 \mathrm{~h}$ in the morning and picked up after $1500 \mathrm{~h}$ in the afternoon and the population of insect pollinators/visitors in each traps were recorded at three stages of flowering period i.e. onset of bloom, full bloom and at the end of bloom at the GPS location of bitter gourd ecosystem $\mathrm{N}$ $23.141752^{\circ}$ and E $83.180472^{\circ}$.

\section{Results and Discussion}

Result shows in habitat-1 the fluorescent colored pan traps during the onset of bloom of bitter gourd ecosystem maximum population of Apis dorsata and Apis indica were recorded. During onset of bloom, full bloom and Apis indica was dominant on end of bloom. During the onset of bloom of bitter gourd highest insect population were recorded on blue pan trap (7.65 insect / trap) followed by yellow pan trap (5.98 insect/ trap) and lowest were recorded in white trap (4.31 insect/trap). During the full bloom maximum insect population was recorded in yellow pan trap (27.33 insect/trap) followed by white pan trap (20.33 insect/trap) and minimum was in blue trap 19.33 insect/trap Table 1a.

Habitat -II maximum population was recorded of Apis dorsata and Apis indica during onset of bloom, full bloom and end of bloom followed by Apis florea, house fly, black ant and small ant. During the onset of bloom higher insect population were trapped in yellow pan trap (21.98 insect/trap) followed by blue pan trap (21.65 insect/trap) and lowest were in white pan trap (15.64 insect/trap). During the full bloom period higher insect population were found (21.98 insect/trap) followed by in yellow pan trap (21.31 insect/trap) and lower insect population were recorded in white pan trap. At the end of bloom maximum population were observed in blue pan trap (17.98 insect/trap) followed by yellow pan trap 13.32 insect/trap Table $1 \mathrm{~b}$. Earlier workers Nuttman et al., (2011) has been reported the utility of Aerial PanTrapping for Assessing insect pollinators, Devi et al., (2016) impact of Habitat on Insect Pollinator Diversity on Coriander Bloom, Devi et al., (2017) has also reported the diversity of Insect Pollinators in Mustard. 
Table.1a Diversity of Insect pollinators/ visitors in bitter gourd ecosystem (Fluorescent colored PAN traps, average of three observations) during 2017-18

\begin{tabular}{|l|l|l|l|l|l|l|l|l|l|l|l|}
\hline \multicolumn{3}{|c|}{ Visitors } & \multicolumn{3}{c|}{ Onset of Bloom } & \multicolumn{3}{c|}{ Full Bloom } & \multicolumn{3}{c|}{ End of Bloom } \\
\hline & White & Yellow & Blue & White & Yellow & Blue & White & Yellow & Blue \\
\hline Apis dorsata & 0.66 & 1.00 & 1.33 & 7.00 & 8.33 & 5.00 & 1.00 & 1.33 & 2.00 \\
\hline Apis indica & 1.33 & 2.00 & 1.66 & 5.00 & 7.00 & 6.00 & 0.66 & 3.33 & 2.66 \\
\hline Apis florea & 0.33 & 0.66 & 1.00 & 3.33 & 5.00 & 4.00 & 3.00 & 2.66 & 2.33 \\
\hline Xylocopa & 0.00 & 0.00 & 0.00 & 0.00 & 0.00 & 0.00 & 0.00 & 0.00 & 0.00 \\
\hline House fly & 0.33 & 0.66 & 1.33 & 5.00 & 7.00 & 4.33 & 1.00 & 2.66 & 2.33 \\
\hline Black ant & 1.00 & 1.33 & 2.00 & 0.00 & 0.00 & 0.00 & 1.33 & 1.66 & 2.00 \\
\hline Small ant & 0.66 & 0.33 & 0.33 & 0.00 & 0.00 & 0.00 & 0.66 & 3.00 & 1.66 \\
\hline Total & $\mathbf{4 . 3 1}$ & $\mathbf{5 . 9 8}$ & $\mathbf{7 . 6 5}$ & $\mathbf{2 0 . 3 3}$ & $\mathbf{2 7 . 3 3}$ & $\mathbf{1 9 . 3 3}$ & $\mathbf{7 . 6 5}$ & $\mathbf{1 4 . 6 4}$ & $\mathbf{1 2 . 9 8}$ \\
\hline
\end{tabular}

Table.1b Diversity of Insect pollinators/ visitors in bitter gourd ecosystem (Fluorescent colored PAN traps, average of three observations) during 2017-18

\begin{tabular}{|l|l|l|l|l|l|l|l|l|l|l|l|}
\hline \multicolumn{3}{|c|}{ Visitors } & \multicolumn{3}{c|}{ Onset of Bloom } & \multicolumn{3}{c|}{ Full Bloom } \\
\hline & White & Yellow & Blue & White & Yellow & Blue & White & Yellow & Blue \\
\hline & 2.66 & 3.33 & 4.00 & 3.66 & 4.33 & 4.66 & 3.00 & 2.33 & 2.66 \\
\hline $\begin{array}{l}\text { Apis } \\
\text { dorsata }\end{array}$ & & & & & & & & & \\
\hline Apis indica & 3.00 & 4.00 & 3.66 & 3.00 & 3.00 & 3.66 & 2.66 & 3.66 & 2.33 \\
\hline Apis florea & 2.33 & 3.66 & 3.00 & 3.66 & 4.66 & 4.33 & 2.00 & 4.33 & 3.00 \\
\hline Xylocopa & 0.00 & 0.00 & 0.00 & 0.00 & 0.00 & 0.00 & 0.00 & 0.00 & 0.00 \\
\hline House fly & 3.33 & 3.00 & 4.33 & 3.00 & 2.66 & 2.33 & 2.33 & 3.33 & 3.33 \\
\hline Black ant & 2.66 & 4.33 & 3.66 & 3.33 & 3.00 & 3.00 & 3.33 & 3.66 & 4.00 \\
\hline Small ant & 1.66 & 3.66 & 3.00 & 2.66 & 3.66 & 4.00 & 0.00 & 0.00 & 0.00 \\
\hline Total & $\mathbf{1 5 . 6 4}$ & $\mathbf{2 1 . 9 8}$ & $\mathbf{2 1 . 6 5}$ & $\mathbf{1 9 . 3 1}$ & $\mathbf{2 1 . 3 1}$ & $\mathbf{2 1 . 9 8}$ & $\mathbf{1 3 . 3 2}$ & $\mathbf{1 7 . 3 1}$ & $\mathbf{1 7 . 9 8}$ \\
\hline
\end{tabular}

Joshua and Hanula (2007) who worked out the efficiency of Malaise traps and colored pan traps for collecting flower visiting insects. Vrdoljak and Samways (2012) has also reported the optimising coloured pan traps to survey flower visiting insects.

\section{Acknowledgement}

The authors are highly thankful to Project Coordinated unit of AICRP on Honey Bees and Pollinators, Division of Entomology, IARI, New Delhi for providing the necessary facilities and technical guidance during the study.

\section{References}

Biennial Report (2013-15) submitted to Project Coordinator Division of Entomology, IARI, New Delhi by Kerala Agricultural University Vellayani, Thiruvananthapuram.

Nuttman, Clive V., Mark Otieno, Kwapong, Peter K., Combey, Rofela, Pat Willmer, and Potts, Simon G. (2011). The utility 
of aerial pan-trapping for assessing insect pollinators across vertical Strata. Journal of the Kansas Entomological Society, 84(4):260-270.

Devi Manju, Sharma Harish K., Sharma P. L., and Rana Kiran (2016). Impact of Habitat on Insect Pollinator Diversity on Coriander (Coriandrum sativum L.) Bloom. International Journal of Bioresource and Stress Management. 7(6):1372-1376.

Devi, Manju, Harish, Sharma Kumar, Thakur, Raj K., Bhardwaj, Satish K., Kiran Rana, Meena Thakur and Budhi Ram (2017). Diversity of Insect Pollinators in Reference to Seed Set of Mustard (Brassica juncea L.).International Journal of Current Microbiology and Applied Sciences. 6(7): 2131-2144.
Joshua, W. Campbell, and Hanula, J. L. (2007). Efficiency of Malaise traps and colored pan traps for collecting flower visiting insects from three forested ecosystems. J Insect Conserv 11:399408.

Kevan, PG (2003). Pollination for the $21^{\text {st }}$ century: Integrating pollinator and plant interdependencies.

Khan, MR and Khan MR (2004). The role of honey bees Apis mellifera L. (Hymenoptera: Apidae) in pollination of apple. Pakistan Journal of Biological Sciences 7:359-362.

Teale, E.W. (1957). Insect friends, Dodd Mead and Co., New York, pp 96.

Vrdoljak, Sven, M. and Samways, Michael J. (2012). Optimising coloured pan traps to survey flower visiting insects. $J$ Insect Conserv. 16:345-354.

\section{How to cite this article:}

Painkra, G.P. 2018. Role of Colored Pan Traps for Insect Pollinator Diversity in Bitter Gourd Ecosystem in Surguja of Chhattisgarh. Int.J.Curr.Microbiol.App.Sci. 7(12): 3116-3119. doi: https://doi.org/10.20546/ijcmas.2018.712.358 